\title{
Deregulation of Electricity Supply Industry in Oman
}

\author{
Hamed S. Al-Maghderi and Bruce Ramsay** \\ ${ }^{\star}$ Ministry of Housing Electricity and Water,Oman, ${ }^{* *}$ University of Dundee, UK.

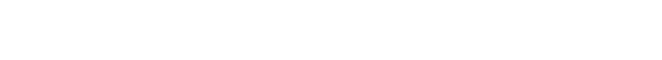 \\ حمد المغري وسوس رطسي

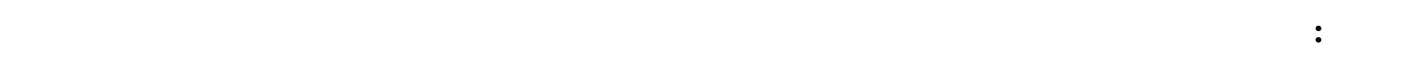

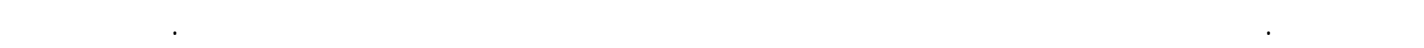
على الطرق المقررة في مجل الخصخصة والتوقعلت في إعادة ششكل وخصخصة مصادر إنتاج الطالة الكهربائية في عملن.
\end{abstract}

\begin{abstract}
This paper examines the opportunities available and the conditions needed for the deregulation of the Electricity Supply Industry (ESI), with particular reference to the Sultanate of Oman. The paper highlights the general issues of regulation required to encourage competition in the ESI. After that, the discussion focuses on regulation methods in the privatized ESI by describing the regulators control through price caps setting for regulatees, the conduct regulation process, the rate of return regulation setting, and the spot market (the pool) contract. Finally, the prospects of restructuring and privatizing the ESI in the Sultanate of Oman are examined by reviewing the current structure of the industry and government objectives in deregulation of the electricity sector as well as the regulation framework.
\end{abstract}

KEYWORDS: Electricity deregulation; Competition.

\section{Introduction}

A round the world, Electricity Supply Industries (ESI) are proceeding with a wide rapid deregulatory reform of their structure and rules. Many of the ESI are currently in transition from a vertically integrated monopoly, to a more open and competitive market. Of the three primary components of the ESI (Generation, Transmission, and Distribution) vertically integrated monopoly, generation is the forefront of transformation and deregulation.

Deregulation has the effect of decreasing government intervention in the sector, which tends to encourage a free market economy. The first consideration of an ESI after privatization is to determine the type of electricity trading arrangements required for meeting consumer requirement in a competitive and efficient manner. Such arrangement must consider prices, continuity, quality, and quantity of supply.

Regulators, prior to privatization, have three objectives in controlling the ESI, namely control of the tariff, conduct and performance. These objectives will change if the ESI is to be subjected to the rigours of the open market. The advent of competition and the need to protect customer rights gives rest to the government's pressing reasons to establish appropriate new ESI regulations.

The regulatory role is instrumental in opening up the ESI markets to investment, by removing the government restrictions on the pricing and quality of the supply and encouraging new entries at different stages of the process. The regulatory effect has made a deep impact on the privatized power sector, which can be seen throughout the power industry as follows (Beesley, 1998): 
1. Generation- rules introduced to allow unrestricted competition have separated generation from the other sector parts and an attempt has been made to establish competitive markets.

2. Transmission- existing networks naturally remain as natural monopolies due to the vast difficulties in building new network grids. However the regulator controls access to the grid, allowing common carriage by third parties and regulates the prices for this service.

3. Distribution- the network is regulated as natural monopoly and does not permit the construction of other networks in order to avoid duplication of the existing network, but the rules have opened the network to common usage with regulated charges.

One of the earlier deregulations of ESI was completed in Chile in 1986 (Yajima, 1997) and then England and Wales followed the footsteps of Chile. Thereafter, many countries followed the reformation conducted in the Chile and the UK, including the Sultanate of Oman.

To understand the deregulation of the ESI in the Sultanate of Oman, we have to establish the objectives and constraints that the government imposes. The government's main objective is an effective and efficient industry structure, with a deregulation framework to balance two sets of objectives. The first is the protection of the long-term public interest, whereas the second concerns the need to ensure that, so far as is practicable, the ESI in the Sultanate of Oman is an attractive investment opportunity for international investors. The government also wishes to promote competition within the ESI in order to reduce the operation costs and to increase the efficiency.

To achieve this, the regulatory framework must strike a balance between providing the government with sufficient control and flexibility to implement changes in policy in order to secure the long-term protection of the interests of the cosumers, and providing an attractive investment climate for international investors to give them the confidence to invest in the ESI.

The ESI in the Sultanate of Oman is currently undergoing restructuring and changing to private sector, which requires a significant change in the regulations in order to meet the requirements of private sector regulations.

Considering all the above circumstances, to what extent does the Sultanate of Oman ESI require deregulation? Do the present rules currently implemented need to be change? The paper will propose answers to these questions.

\section{General Issues of Regulation}

The decision to privatize the ESI introduces the need for changing the regulation to take the new structure and try to regulate within this externally determined structure. The regulation implemented in the public sector is not an option for any country serious about encouraging private investment in its ESI. Private investment requires a new model of regulation that is limited in scope and transparent.

Therefore, privatization puts the regulators in the position of having powerful and immediate impact on the evaluation of the electrical industries, and also has an ongoing role to preview the procedure of the industry's revaluation.

\section{Requirement of Regulation in the ESI}

One of the main criteria of privatization is to reduce the regulation in the ESI, and encourage the competition. This is achieved in most parts of the sector, but some functions, those regarded as natural monopoly operation, require being under regulation. This is appearing in naturally monopolistic functions (transmission and distribution networks). The needs to monitor and control monopoly in the transmission, distribution, and system control are very essential because the probability of exploitation of lack of alternative power sources for the customer is very high. A natural monopolist will take into account his own cost situation together with demand conditions 


\section{DEGREGULATION OF ELECTRICITY SUPPLY INDUSTRY IN OMAN}

when setting output prices. He will charge a price higher than the efficient price level, which is a profit beyond compensation for the cost of capital (economic rent). This is will be directly reflected in the retail price which may cause a social and political impact.

However, the coexistence of competitive supply and monopolistic activities (owner of the network) in the deregulated ESI, gives the regulator a dual role in monitoring both these parts and in overseeing the vital access for competitors to the network. Although his job will be more difficult if the monopolist owns the network and tries to restrict competition, in such cases regulators' options in providing regulatory framework for this industry can be introduced by defining the objectives for the regulation. In the UK, Professor Stephen Littlechild - first regulator of the UK ESI set out objectives for regulation. He suggested five objectives for regulation:

- Protection against monopoly,

Efficiency and innovation encouragement,

- Low cost of implementation,

- Promotion of competition,

- Maximization of proceeds from sales and enhancement of the utilities' commercial prospects (Littlechid, 2000).

The economic description for the regulation objectives is that a regulator should maximize the weighted sum of customers' surplus and suppliers' profit. The relation of these two components in the regulator's objective function affects the increment weight of customer surplus by decreasing the price. To explain this relation, suppose the weights are equal, so that allocated efficiency (relation of price to appropriate costs) is achieved by marginal cost pricing. If the revenue is insufficient to cover the total costs of the company, price should be increased above marginal cost for the demand, which is least responsive to such price increment. Similarly, if the company declares high profits, the regulator's intention could be very considerable to control the profit margin in line with the regulation objectives.

\section{Regulation of Monopoly in the ESI}

Greater efficiency of the privatized ESI can be achieved by regulation promoting competition and controlling monopoly. The power of monopoly can be reduced, and breaking up cartels or reducing the size of the ESI firms could increase that efficiency and competition.

In recent years, however, technical progress has been increasing too rapidly to allow most monopolies to remain immune from potential competition. This is most obvious when there are alternatives to monopoly network, as in Combined Cycle Gas Turbines (CCGT) and Combine Heat and Power (CHP) are reversing some of the advantages of scale in electricity generation. In both these cases it may eventually prove cheaper for large consumers to bypass the natural monopolist's transmission and distribution system.

There is no strong economic argument for profit control in the ESI with a high rate of technical innovation as long as there is free entry and the interconnection as regulated predatory behaviour can be controlled effectively. There is no restriction on price discrimination and it is sufficiently and technically feasible for the enterprise to get near enough to the economic efficiency implied by competitive output levels for any remaining inefficiencies to be of less cost than the probable costs to the customers of regulation.

\section{Regulation in the Privatized ESI}

Regulatory policy is designed to meet the objectives of privatization and the public interest. Policy creators recognize this in many aspects, though in practice the focus has been almost exclusively on efficiency. This is reflected in the design of the regulatory framework for deregulated utilities in many countries, for example the UK and the USA. The regulatory regimes 
have been effective in promoting and protecting the interests of customers and preventing the earning of excess profits through the exploitation of market power by the ESI utilities.

Different regulatory methods are used in regulating the ESI after privatization; the following explains some of them:

\subsection{Price Cap Regulation}

Price cap regulation imposes a restraint on the rate of increase of prices with the now famous RPI - X formula introduced by Professor Littlechild (Helm, 1995). The formula allows the electricity company to increase its rates on regulated services from a base level by the change in the Retail Price Index (RPI), reduced by the expected rate of increase of productivity X in the ESI.

The main target in this regulatory concept is the price, which comes closer to reflecting the underlying aim of customer protection. RPI-X is based on capping prices rather than profits, which pushes the company to achieve productivity with efficiency, and allows the company itself to control price reductions. Regulatory intervention will be low because it only requires the calculation of the price indices with no need to measure the assets value or rates of return for the company. The only requirement from the company is to be sure that the average value of price increments in one year does not exceed the percentage increases in the RPI-X.

For this reason price cap regulation produces incentives to improve the efficiency, because the utility carries full responsibility for its costs once the price cap has been set. Customers benefit from efficiency improvements in two respects, because a price control can be set to reflect both the efficiency improvements shown during the previous price control period as being actually achievable, and the further efficiency improvements that might be reasonably expected over the duration of a new price control. In addition RPI - X price control regulation was designed to be predictable, allowing electricity companies to plan several years in advance on the basis of four or five year periodic reviews.

At each periodic price control review, consideration is given to the form of the price control, in particular whether RPI-X or some other form of price control such as a sliding scale or a profit control is the most appropriate for the regulation of the companies. A sliding scale control might specify that if profits move outside specified limits, prices would have to be adjusted downwards or upwards, for example to share between customers and shareholders the consequences of unexpected movements in costs. Under a profit control system prices might be adjusted annually in the light of actual expenditure, including a specified profit rate of return.

\section{Conduct Regulation}

Conduct regulation, mainly used in the USA (Tenebaum et al, 1992) concentrates on the direct administration of the operation and investment of the regulated utility. It takes on two principle forms. The first one is called green regulation that is usually described as the Integrated Resource Planning (IRP) and allows the regulator to be more involved in the companies planning and selection process. This is placed under the belief that the electric utility always produces the wrong product. IRP process argues that the utility should be to produce energy services not just electricity. The method of the IRP process indicates that electricity is under priced because electricity utilities and their customers do not see the full environmental costs of operating a generating plant. IRP said that the utilities have little incentive to offer demand side services, which would lead to a reduction in their overall profits.

The second conductive regulation is the introduction of competition in many different ways. For example, the regulator gives detailed guidelines on how to introduce competition in the new requirements for generating capacity. Once the generating capacity is completed, there will be another regulatory review for the company's purchase decision made under the guidelines of the competition.

\section{Rate of Return Regulation}

Rate of return regulation is the most commonly used form of the ESI regulations in the United States, and has been in use for decades (Tenebaum et al, 1992). Its aim is to reduce the power of 


\section{DEGREGULATION OF ELECTRICITY SUPPLY INDUSTRY IN OMAN}

natural monopolies (transmission and distribution) to restrain output, raise prices, and realize supra normal profits. Rate-of-return regulation is also called cost-of-service regulation in that it essentially allows electricity companies to pass through those costs which are deemed necessary by the supervising regulatory body to ensure that an adequate level of service is provided to end users of the electricity.

Rate-of-return regulation has both advantages and disadvantages. Rate-of-return regulation allows representation of the public in matters regarding electricity company price setting, rates of return, and investment so that the company cannot restrain supply and realize monopoly profits. Also rate-ofreturn regulation offers utilities few financial incentives to aggressively restrain or reduce operating costs.

The disadvantages of rate-of-return regulation can be summarised by that saying detailed industry data is deemed an excessively expensive effort that will require a large bureaucratic structure. Further, information the regulator obtained from the regulated industry was always incomplete, relative to the information possessed by the industry, leaving the regulator in an inferior negotiating position relative to that of the industry.

\section{Spot Market (The Pool)}

The spot market in the electricity industry can be defined as the immediate delivery of energy with prices depending on the supply availability and the overall volume of demand. It can be considered as a set of bilateral deals, and negotiation for selling power between the generator and buyer to the customers. The spot market is judged by settlement rules and definitions which can be summarised as follows:

In ideal conditions each generator generates exactly the amount of power needed for the demand connected. However, this is impossible due to the difficulty in operating plants on this basis because customers' demand could rise or fall faster than the generator is able to alter its output (e.g. with an ON/OFF appliance). It is also impossible because of a generator breakdown that would need to be covered immediately in order to keep the electricity supply constant without any interruptions.

Due to the reasons above there will always be a difference between the contract amount and generation production, which continuously produces an imbalance of power and should be settled. For these reasons the arrangement of selling, purchasing electricity, and last minute transactions limit traders in making their own purchase and sales, as they need dispatchers and Market Operator (MO) to settle every deal, or solid market terms to avoid any conflicts that may arise (Hunt and Shuttleworth, 1999).

The MO directs the electricity spot market so that all sellers receive their money and fulfil their contracts if the amount of power agreed for delivery is delivered completely, and all buyers pay for the uncontracted off-take if the consumption exceeds their contracts.

Among regulation methods, spot market in the electricity generates large customers with access either directly or through traders. The Electricity Pool supports competition in supply, where customers can choose their supplier. The Electricity Pool mechanism enables competition in generation, in order of which generation plant should be used, and permits all prospective suppliers to purchase in the wholesale market on the same basis.

\section{Deregulation of the ESI in Oman}

In Oman, the ESI is vertically integrated as directed by the Ministry of Housing, Electricity and Water (MHEW). The process of privatisation for the ESI in Oman is designed to introduce competition by completely privatizing all the electricity industry with the exception of rural areas, which will remain in public hands.

The new reform of the industry recognises five functions: generation, transmission and system control, distribution and supply. The ESI will be unbundled to different companies with new 
regulatory framework aims to promote competition and ensure that the remaining monopolies do not exploit the advantages of privatization.

\section{Current Structure of Oman ESI}

The ESI in the Sultanate of Oman is currently owned and operated by the government, through the Ministry of Housing Electricity and Water (MHEW). The Ministry operates as a vertically integrated utility. It is responsible for:

1. Determination of national electricity and desalinated water policy.

2. Planning and studies required for the electricity and drinking water in the country.

3. Ownership and operation of all generation, desalination, transmission, distribution and supply of electricity to customers, except Manah power project and the forth coming Al-Kamil power project.

4. Self-regulation i.e. setting specification for the materials used in the electricity industry and regulation of the tariff of energy consumption.

MHEW is separated into directorates general for both water and electricity to meet the above responsibilities. The unbundling process will be mainly in the directorate general of electricity, which is responsible for several organisation departments providing a very wide range of control for the ESI in Oman.

\section{New Structure for the ESI in Oman}

In order to develop a structure and create strong success of privatization where investors will be attracted to invest in the electrical power industry, the Omani government demonstrates and establishes an absolute commitment to the proposed privatization process. The government policy for privatization is to limit the existing power assets within MHEW to the following companies working under the law of industry.

1. Three generation companies

2. Three distribution companies

3. Transmission Company with function of operating the new dispatch centres.

4. Power procurer, as a single buyer of electricity from the generators.

5. Remote systems company, responsible for the ESI in villages and on islands.

Also the establishment of regulator with well-defined rules and principles is very essential for privatizing the ESI. The regulator must be capable of regulating the new structure of the ESI to maintain the system in competitive mode, and there by encourage investment in the electricity sector in the country.

\section{Oman Objectives from Privatization}

Many countries worldwide are considering privatization or the restructuring of their electrical energy industries. The main reasons are to increase efficiency and competition in order to have more choices for the economy and customers. Oman is one of these countries tending to privatize their electrical industry, seeking to broaden the economy by establishing new industries.

The following objectives are what the Omani government will achieve from the privatization of the electrical power sector (Mne, 1999):

1. Security of electricity supply to the customers, which is a primary concern for the government. Privatization must improve over time with less investment in installation of new generation, transmission and distribution capacity. 


\section{DEGREGULATION OF ELECTRICITY SUPPLY INDUSTRY IN OMAN}

2. Withdrawal of the subsidies from the power sector; this is one of the main objectives of the government in the long term. Privatisation will improve that by introducing competition into the sector.

3. Fuel efficiency; until now the Sultanate uses open cycle power generation turbines in most of the power generation stations. With new off-takers being attracted and reserves not inexhaustible, the government needs to reconsider the value of gas and to make decisions on the efficient usage of fuel.

\section{Privatization Recommended for Oman ESI}

When considering the optimum privatisation technique for the Sultanate of Oman ESI, there are two important factors which need to be taken into account (Mne, 1999):

a. The size of the ESI is very limited and has a fragmented structure, with many parts of the networks not being interconnected. The Ministry of Housing Electricity, and Water (MHEW) is currently trying to improve the situation by increasing investment in the transmission system.

b. The government's objective of retaining a significant shareholding when the ESI is finally floated on the Muscat Securities Market (MSM).

From experience of other countries like the UK, it is clear that the most significant investor interest is likely to be in generation and consequently this should be the initial priority for the government to privatise.

A successful programme of privatisation of the generation assets will create a solid foundation for the privatisation of the transmission and distribution networks. Due to the lack of a fully interconnected and secure transmission system, it should be recognised that urgent and extensive investment is required in the system in order to create the necessary infrastructure of an efficient privatised power system.

\section{Conclusion}

Deregulation of the Electricity Supply Industry (ESI) has gained popularity in several countries around the world. This is due to the desire to minimize political interference in the operation and management of the utilities, and the availability of a soft budget for the industry.

The need for competition and greater economic efficiency has accelerated the process further. Therefore, deregulation has become an important issue towards improving the ESI performance, and achieving the above objectives.

Once a country decides to deregulate its ESI it has to consider carefully some important issues so that deregulation can take place successfully. These include:

1. The establishment of a regulatory framework with strong political backing and regular public information.

2. Transparency and clarity.

3. Gradual restructures to prepare the ESI for deregulation.

4. Promotion of private sector participation.

Along with the ESI restructuring, a powerful regulator must be established to oversee the procedures set in place for the industry's re-evaluation. In addition, where competition may be not completely achieved (i.e. transmission, distribution), the monopolistic situation has to be regulated. 
The ESI restructuring will only succeed when reformers consider both the industry and the way it is regulated.

The regulation scheme for the ESI must provide incentives for efficiency in operation, pricing and investment. Thus, the choice of a regulation scheme- be it a price-cap, rate-of-return, or conduct regulation, depends on what kind of effect the regulation on the regulated industry is to achieve. A balance must be maintained between satisfying the interest of shareholders, customers and government.

The participation of the private sector in infrastructure development like the ESI leads to an improvement services to the customers, through an efficient and economic process, thus minimizing demands on government resources. This provides an encouragement for the deregulation program in Oman, which is moving towards greater competition and private sector participation in its own ESI. In view of the rapid growth of the Omani ESI and the forecasted increase in energy demands, deregulation of the ESI is the only way to alleviate any problems.

The following recommendations are hereby proposed for a successful restructuring of the Omani ESI:

1. Establishment of an independent regulator with well-defined rules and principles prior to any unbundling or privatization process.

2. Unbundling of the ESI by splitting it into three generations companies, five distribution companies according to the existing regions of Oman (Muscat, Batinah, Dakhliyah, Dahirah, and Sharqiyah), one transmission and dispatch company to operate the connected ESI independently and one power purchase company as a single buyer for the electricity in the Sultanate. The remote systems in villages and islands should be unbundled and vertically integrated under one company. This is should be held for about three to five years to create incentive improvement in the ESI efficiency by new management and reduce central management from the head office.

3. Open competition between the distribution companies, through given rights to the customers above $1000 \mathrm{kVA}$ of load to subscribe to any of the distribution companies that he feels will supply efficient energy to his residence, factory...etc. This will introduce competition between the distribution companies to improve their distribution electrical networks and to work in a more efficient way, which will reflect directly in reduction of losses. Therefore the government subsidies will decrease.

4. Privatization as a follow-up to deregulation - if the Government is still interested in privatization of the ESI after restructuring, it should be implemented only on the generation for a start. Other parts of the ESI could be privatized later in stages as a joint venture with investors has technical capability to improve the efficiency and reduce the losses in the ESI networks. This is due to the limited size of the ESI, where it is difficult to achieve any competition, and the heavy subsidies in the system that the government will face a problem in eliminating in the short term. In addition, there were also agreements signed by the government with several IPPs (United Power Company in Manah, AL-Kamil Power Company in AlSharqiyah, and Barka Project currently under negotiation). Hence, open competition will not be possible in the near future.

\section{References}

BEESLEY, M., 1998. Regulating Utilities: understanding the issues London Business School in association with the Institute of Economic Affairs (IEA), Reading.

HELM, D., 1995. British Utility Regulation Oxford University Press. 


\section{DEGREGULATION OF ELECTRICITY SUPPLY INDUSTRY IN OMAN}

HUNT, S., SHUTTLEWORTH, G., 1999. Competition and Choice In Electricity, England: John Wiley \& Sons.

LITTLECHID, S., 2000. Privatisation Competition and Regulation. The Institute of Economic Affairs, London.

OMAN. MNE. 1999. Privatisation Study. Ministry of National Economics, Oman.

TENENBAUM, B., LOCK, R. and BARKER, J. 1992. Electricity Privatisation, Structural, Competition and Regulatory Options. Energy Policy, December 1992, pp.1134 -1160.

YAJIMA, M., Deregulatory Reforms of the Electricity Supply 1997. Quorum Books.

Received 12 June 2001

Accepted 9 February 2002 